KOME - An International Journal of Pure Communication Inquiry

The Cyborgian Limit? Opening Volume 6 Issue 1, p. 75-93.

(C) The Author(s) 2018 Sequences as Cultural Analyses

Reprints and Permission: kome@komejournal.com

Published by the Hungarian Communication

Studies Association

DOI: 10.17646/KOME.2018.15

\title{
Constance Goh
}

\section{Centre for the Study of Post-Conflict Cultures, The University of Nottingham, UK}

\begin{abstract}
With the advent of digitalisation, digital soft-wares enable the creation of extraordinary opening sequences, one such being the animated opening credits of Mamoru Oshii's 1995 Ghost in the Shell, recently reproduced in Rupert Sander's 2017 live-action film. This paper rethinks psychoanalysis and explores this analytic approach to film in and through its opening sequence by way of the following inquiries. What is the relevance of Lacanian psychoanalysis to the question of gender in the twenty-first century if gender is supposedly one of the defining ontological facets of human beings? Given the recent attention to the place of feminist politics, can we say that Haraway's cyberfeminist take still has challenging potential in contemporary postgendered reality when Haraway herself has called her brand of politics a postgendered one? What if that which necessitates an address is not so much the place but also the temporal event that "animates" an individual's consciousness, especially if perception is somehow tied to how we remember our past? Investigating how one's imagination is "animated" in one's encounter with an aesthetic object, this paper will elaborate the epistemological import of Lacanian psychoanalysis with critical analyses of the opening scenes of Tim Burton's 2014 Big Eyes, and the aforementioned versions of Ghost in the Shell.
\end{abstract}

Keywords: Opening Sequences; Lacanian psychoanalysis; Film and Animation; Popular Culture; Big Eyes; Ghost in the Shell

But, once adopted into the production process of capital, the means of labour passes through different metamorphoses, whose culmination is the machine, or rather, an automatic system of machinery (system of machinery, the automatic one is merely its most complete, most adequate, and alone transforms machinery into system), set in motion by an automaton, a moving power that moves itself; this automaton consisting of numerous mechanical and intellectual organs, so that the workers themselves are cast merely as its conscious linkages. In the machine, and even in machinery as an automatic system, the use value, i.e. the material quality of the means of labour, is transformed into an existence adequate to fixed capital and to capital as such.

(Marx, Grundrisse, 692)

You are more than just a weapon. You have a soul... a ghost. When we see our uniqueness as a virtue, only then will we find peace.

(Daisuke Aramaki, Ghost in the Shell)

Address for Correspondence: Constance Goh, email: timbre0403[at]gmail.com

Article received on the 1st November, 2017. Article accepted on the 17th June, 2018.

Conflict of Interest: The author declares no conflict of interests. 


\section{Introduction}

This paper is written due to the fact that filmic openers, besides the website, Art of the Title, have not been given its due attention as works of art. Art of the Title focuses primarily on the fonts of titles, text types that are appreciative of the filmic cast and crew, a laudable endeavour that I shall take on further by directing attention to its visual dimension. For those interested in openers of film or television series, the Art of the Title also historically contextualises title sequences created by Patrick Clair, Saul Bass, Kyle Cooper and Thierry Kuntzel. The latter, considered the first creator of titles by Thomas Elsaesser, is a video and installation artist, who directed the openings of Fritz Lang's films $M$ (1931) and the Most Dangerous Game (1932). As a film theorist, Kuntzel's creative premise is to give "an overview and a formal analysis" of how a title sequence can be a dynamic process of analysis, the opener as a "mini-film" working in a post-filmic manner (Elsaesser and Hagener, 2005). More importantly, Kuntzel's concern with the profound (sub)liminal effects of the iconic, the visual impacts of both word and image, aptly described in MoMa's memoriam to his passing as "what happens beneath the surface of representation beyond a narrative storyline" (emphasis mine), is crucial not only to this paper on the aesthetics, the function and the purpose of opening sequences; it indicates how the audience achieves semantic denouement through the viewing process, narrative or otherwise. The above emphasis is also a pointer to how the deep-diving cybernetic figure of Rupert Sanders 2017 Ghost in the Shell is an apt symbol of how one textual layer, the denotative, dialogically interacts with another layer, the connotative, so as to arrive at film analysis. Theoretically framed by poststructuralist thought, and thereby predominantly psychoanalytic, this paper reconsiders the opener as a liminal space, at once addressing neither an absolute narrative nor a complete theoretical frame, that simultaneously demarcates and adjoins the viewer and the viewed, explaining not only the various aspects of the opener but also its location of being neither completely on the inside nor the outside.

Opening sequences can be suggestive means of access into the film: some are designed as aesthetic commentaries of the films; others indicate thematic concerns whereas some provide inscriptive backstory of the film of which the titles of Ridley Scott's 1982 and 2017 Blade Runner series are exemplary. The title opener to Blade Runner 2049, clearly a tribute to Scott's 1982 Blade Runner, indexically functions as if it is a visual establishing shot, narratively setting the filmic backdrop, working in a manner dissimilar to contemporary opening sequences, which are more disjunctive and thereby surrealistic. Notwithstanding the fact that most dystopian narratives, contemporarily classified under "speculative fictions", have rather simple fictional arcs, it is the post-human characteristics that make mysterious the cybernetic personas of the Blade Runner series, corresponding to the often theorised "uncanny valley" of digital animations, uncanny because these cybernetic figures are just too familiar to us. This enigma is depicted atmospherically in Scott's use of colour and music, which are cryptically dark and starkly sonorous, itself a cinematic allegory of the psychoanalytic knot of the real, symbolic and the imaginary that gestures, at the same time, to how interpretatively opaque some openers can be to some audience.

As a precursor to many science-fictional films, Blade Runner can be argued as having comparable traits to Oshii's Ghost in the Shell, both stylistically or thematically. This paper works with cultural analysis, which explains the poststructuralist as well as post-Marxian analyses that includes Donna Haraway's socialist feminist take, in order to philosophically address the manner in which filmic interpreters work with title openers to gain entry into the film. More significantly, this paper, in line with its political proclivity of being attentive to 
the repressed, reworks the previously semiotic emphasis on the signifier in order to redress the postmodern conceptualisation of the materiality of the denotative, and, by extension, the connotative signifier in its reflective slant, a mirroring that explains how the science-fictional cybernetic has been, from time immemorial, more about man than machine. The mirror concept indicates as well how the various theoretical strands interweave: the Lacanian mirror stage that enables the formation of the $I$ function can be analysed in relation to the subjectivity of the $I$ in the feminist standpoint theory, the precursor of which is Haraway's cyberfeminism. Moreover, the mirror stage is a liminal stage wherein the infant's ego is constructed, the spectral ego accorded by the wholesome refection s/he sees that becomes the social ego in and through Symbolic processes of socialisation and naturalisation, a transition that, in Lacan's psychoanalytic triad, dramatises a downward move from the imaginary to the symbolic on the side of that which is true: the wholesome selves we apparently experience are limited by the social structures and strictures we inhabit.

Phillip K. Dick, although not in the know of psychoanalysis, seems to have arrived at the same philosophical conclusions with "Do Androids Dream OF Electric Sheep?" Rachael, the ethereal female protagonist in Blade Runner, may have unsettled the audience of the nineteen eighties with the unfortunate discovery of her android status, the prophetic stuff of dystopic science-fiction. but it is the ambiguity of the ontological identity of Rick Deckard, the replicant hunter of the Nexus 6 insurgents, which makes Scott's 1982 sciencefictional adaptation of Dick's "Androids" philosophically iconic - oddly invoking Mamuro Oshii's Ghost in the Shell a tentative response to a question man will never be able to answer absolutely - thereby qualifying this address on the visually adapted versions of Dick's story given that the stylistic impact of Ridley Scott's Blade Runner could be felt throughout the decades that follow, a source code that proliferates to the differentiated visual codes of other speculative fictional films.

Scott's titular blade runner whose job is to hunt and put down robots, which in the opener is called "retirement", was assumed human initially by viewers whose frames of mind have been deeply ingrained by dichotomous socio-political underpinnings. Its strong cybernetic undercurrents, however, visually signals the rise of what has come to be known in the twenty-first century as the "post-human", a term that supposedly encompasses humanoids, androids, robots and cyborgs, although it mimetically points to homo sapiens rather than the humanoid by virtue of the fact that we are traced by the "inhumanness" of language, as indicated by Jacques Lacan's infamous "the unconsciousness is structured like a language". This is also the reason for including an analysis of Burton's Big Eyes whereby the female protagonist finds self-redemption in full expression, bringing to the fore the linguistic grammatisation upon which consciousness is founded. Blade Runner 2049 paratextually confirms the humanoid nature of the hunters, belatedly exposing the sameness that underpins both the filmic opponents. Despite this, I have to remark upon a slight difference detected in Scott's 1982 and 2017 title sequences: the constructive appearance of a tree, perhaps the tree of life, and thereby knowledge, that follows the total blackout that initiates the 1982 version.

This paper reworks Gerard Genette's concept of the paratext to understand the function of "opening sequence" rather than "title sequence" because it does not address specifically the alphabetic. It concentrates on the visual imagery used in what is commonly known as "title sequence" in order to analyse how screen images symbolically or stylistically evoke the viewers' mental processes. The interstitial location of openers indicate that they are not only aesthetic entrances into film; they provide cultural analyses of potential overlaps 
- what some would call the "mirror" effect - between the imaginary world of the film and the real world by virtue of the mimetic quality of moving pictures, both elaborated by films adapted from a graphic novel as well as a biographical film, visual depictions of varying degrees of realism that also question the very nature of reality. This correspond to what Clive Myer designates as the diegetic and non-diegetic spaces of the "not-yet-film, film and notfilm" in "Theoretical Practice, Diegesis is not a Code of Cinema" to which I shall respond by adding terms such as "pro-filmic, filmic and post-filmic", categories that are aligned to the discursive classifications of "film" as the material production itself, "cinema" as the corresponding discussions on film, analytical or narrative, and "movie" as an indicator to the economic and financial aspects of the film industry. The term, "filmic", refers to the diegetic space of the movie while "pro-filmic" gestures to the so-called extra-diegetic elements that have effects on the filmic diegesis and "post-filmic" points to the activities that come after the film, including reviews, commentaries and critiques. These terms are attended to here because they bring to the fore Genette's detailed analysis of the literary diegesis which has been appropriated by film theorists in their discursive analyses of film. Myer's chapter in Critical Cinema accounts lengthily the historical development of cinematic diegesis, including a brief mention of Genette's conceptualisation but not the etymological significance of the paratextual: the word-forming "para" signals both the "beyond", "contrary" or "altered" and "defense" or "make ready", definitions complicating the very concept of the filmic opener.

This rethinking of the opening scene, with the concomitant terms mentioned, already implies a "network" structure, an intertextual homage to the (post)structuralists' analyses, that permit communicative flows that are de-centralised passages, given that this cinematic epoch can be described as one of sequels, anthologies or series and remakes, a chain of links which I shall elaborate here with the paratextuality of the opener, discursively bringing to the fore what Genette in his footnote calls the slave to the master of the main literary or filmic text. And yet the aforementioned films can be viewed individually because they are feature-length films that are framed with individual plots. Thematic or intertextual connections are not always made by the viewers, especially those not looking for these allusions.

This analysis, predicated on paratextual images, correlates to my attention on the socially underprivileged, "the second sex" of Simone de Beauvoir or the ones on the lower social rungs, and focuses on Genette's concept of the "peritext", a paratextual category that encompasses titles, epigraphs and prefaces, because opening sequences are visual correlatives of these accompanying texts, figurative doors opening onto inscriptive passages other than the filmic wherein the inscribed letters can be posted. Without discursive endeavours, we will not have the Derridean "supplement", a signifying term he uses in his focus on textual "dissemination" or the Lacanian "objet petit a", an object that allows imaginary projections, a "jacking in" described in High Tech Orientalism. This is a process made by the viewers as they mentally gain access into the screen, psychoanalytic bridges that allow different types of interpretative traversals, sense-making sojourns that paradoxically make obvious the question of the hermeneutic, the Derridean outside of nothingness that Scott's 1982 opener inadvertently allegorised.

Elsaesser, too, speaks of thresholds and paths that lead the film from and to the commercial machinery of film production, distribution and exhibition, which can be used to speak of the potential ramifications of too tight a capitalistic hold on film productions. As indices to the temporal underpinnings of Genette's intertextual analysis, gestations on 
"spatium", the space of time instead of an actual place, are prompted wherein both the "space" of liberation and the "place" of security can be thought. The screen as door encourages processes of identification and projection, connotative processes that arguably incite psychoanalytic attempts to diagnose the patient's "symptoms".

Here, I shall use this method to diagnose the "symptoms" of the dream-works of films because most opening sequences actually make manifest how dreams flow: a manner not unlike the Joycean stream of consciousness. While most critics think that "context" provides semantic stability, it is "context", whether historical or cultural, that makes obvious the yetto-be-semantic slippage of the signifier. Buttressed by retrospective and anticipatory moving images, with multiple inward and outward brooks of immersive viewing experiences, the viewing process, further reinforced by classical Hollywood continuity filming, permits the imaginary insertion of the viewer making the audience lost in their illusory submersion. The viewers feel empowered by the visual immediacy of a cybernetic projectile leaping off a corporate office building, identifying with the cybernetic protagonist. Driven, of course, by a potent narrative on how anyone can be a superhuman being with the right technological enhancement, the multiple versions of Masamune Shirow's Ghost in the Shell affirm even as they point to the dangers of a world overwhelmed by technology.

The continuity-editing technique of Hollywood, a process that emulates the signifying linearity of human consciousness, also indicates how human consciousness can be commercially manipulated, an unpalatable underside represented by the ubiquitous holographic images of cyber-enhancement implants that advance our cerebral faculty and sensorial capacity in the 2029 dystopian world of Ghost in the Shell. This paper rethinks how our psychanalytic approach to film can be addressed with its opening sequence by way of the following inquiries. What is the relevance of Lacanian psychoanalysis to the question of gender in the twenty-first century if gender is supposedly one of the defining ontological facets of human beings? Given the recent attention to the place of feminist politics, which can be counter-argued with Jacques Derrida's calling to question the place of women in his 1982 interview, "Choreographies", can we say that Haraway's cyberfeminist take still has the same challenging potential in contemporary postgendered reality when Haraway herself has called her brand of politics a postgendered one? What if that which necessitates an address is not so much the place but the time of the event that "animates" an individual's psychic process, especially when perception is somehow tied to how we remember our past? In other words, what can one deduce about popular imagination when human agency is empowered by that which can be described as "phantasmatic"? What can the stake be in a revolutionary actualisation motivated by fiction? These inquiries signal the rise of the postgendered non-binary and the propagation of divides beyond that of the conventional oppositions between the virtual and real, the apparitional and the substantial, by virtue of the advent of digital media. While Haraway's socialist-feminist discourse has been used to support post-filmic analyses of Ghost in the Shell such as Natasha Miner's 2014 essay "Technology, Psychology, Identity: Ghost in the Shell and hack//Sign" and Marie Deanne Theresa O Correa's review "Ghost in the Shell: A Cyborg-Feminist Review of Mamoru Oshii's Animated Film", I shall suggest that a close reading of Oshii's Ghost in the Shell subtly subverts Haraway's celebratory cyberfeminist rhetoric when the central cybernetic character self-consciously questions what it means to live as a man-machine hybrid, noting that the hyphenated identity here initiates already a shared existence. More importantly, the fact that Motoko Kusanagi poses questions already signals her self-aware sentience. 
Of ontological significance to this analysis is the "mirroring" mentioned in the introduction of Techno-Orientalism by David S. Roh's, Betsy Huang's and Greta A. Niu's as a citation from Toshiya Ueno, "the mirror of cultural conceit" $(2015,3)$ or explicated in "High-Tech Orientalist" as multiple reversals - distortions attesting to this thesis the depicted cyborgian is in actual fact science-fictional commentaries of homo sapien. The inversion of the denotative mirroring of the imaginary by the symbolic after the connotative mirroring of the imaginary are intuitive manoeuvres provoked by sense-making processes, sensibly premised on the non-sense of unfiltered noise. Besides the human-android confusion is the discursive hegemony implicated by the power relays between the West and the East, an issue of labelling that Techno-Orientalism addresses by shifting focus to how the culturally dominated empire strikes back. Wester Wagenaar's "Wacky Japan" briefly chronicles how first-wave Orientalism, the postcolonial creed of Edward Said, moves to the second-wave of Techno-Orientalism, which critiques the self-constitutional dominance of the Western othering gaze, that deviates to the self-orientalising third-wave of the Eastern idiosyncratic, a self-fashioning that hides so as to captivate. The fact that the imagistic opener contradictorily strips the cyborgian protagonist with a visual representation of its construction expresses rather crucially the "nothingness" of the textual outside. In other words, s/he, when denuded of her facial features and cybernetic covering, is not anything but a technologically wrought anatomy, a metallic mirror of organic bones.

\section{Suture in and through the Screen: The Post-Filmic within the Filmic}

Contemporary Hollywood is known now for its appropriation of the self-aware techniques of art-house productions, arguably the filmic niche that poses visual critiques of cultural commodification and massification, politics of cinema that points to how the extradiegesis of the post-filmic can be found within the filmic, even as Hollywood retains and intensifies its own norms. This sees a discerning film director such as Tim Burton paying homage as well as subtly undermining popular culture by making a biographical film on

Margaret Keane who was psychologically overwhelmed by her big-eyed waif paintings. His film bears witness to how hyper-industrialisation in real-life, the RL of techno-orientalism, exacerbates psychological alienation, while a creative Oshii converts Shirow's manga, Mobile Armoured Riot Police, to a thrilling, action-packed filmic virtualisation that can be re-projected to real-life instances of "industry". These films signal a shift to post-classical styles, one surprisingly complying with the standardised norms of narrative construction, albeit still retaining some of the filmmaker's surrealist tendency, whereas the other obviously challenging it by making an animated film quite unlike Disney animations, although, historically, the larger-than-life female eyes of popular Japanese anime are adopted from Disney's productions.

This paper investigates how opening sequence bridges the audience and the film, a comment that paradoxically points to a gap between the viewers and the viewed, a manoeuvre that sees this "mini-film" as an aesthetic review of what Lacan calls the "objet petit $a$ " or Derrida's "supplement", the $a$ of his differance signifying the etymologically archaic "idiotic" appendices, etymologically deriving the psychically idiosyncratic, the significance of which is made pronounced by what the blogger of le0pard13.com describes as "methinks" in his brief reading of Sander's and Oshii's openings to Ghost in the Shell. However, a word of caution to those unfamiliar with poststructuralist theories, these two concepts are distinct in their gendered senses. In fact, the only similarity they share is the role of a connective support when placed in a communicative context, a linking device, here 
refigured as the "screen", that actually points to communicative gaps rather than the seamless reality of which the technophiles dream.

By virtue of the fact that this analysis predicates itself on how the cinematic frame activates human emotions at a meta-level, it addresses the manner of transcending divides rather than the postmodern blurring of divides, a manoeuvre that can be called "frameless framing", with an aerial view that qualifies the comparability amongst the discussed opening sequences. Thus the titular use of "cyborgian" here, just like the opening scene to the film, can be inferred as an overriding of albeit via an implied acknowledgement of these limits. More importantly, it reconsiders how the (in)voluntary "subjective" submergence of the audience can lead to action in real-life, making a transition from the secondary level of connotation to the primary, denotative plane. It can be described as a "passing" from virtual reality to actual reality, a passing, which, in psychoanalytic theory, is animated with pathos rather than logos because it involves the desirous processes of fetishisation and reification. As a prolegomenon and an addendum, the opening scene, due to the way it is designed, not only serves as an introduction to the cinematic event; as an almost "eternalised" entity, it also reflects the aesthetic strategies, narrative devices and thematic concerns of the film. This "points of entry" into the film can be used to subvert the "frame by frame" linear convention that most practitioners use in describing film production because it can either engage a viewer with its drawing potential or, not unlike "the breaking of the fourth wall" technique, intervenes the viewing experience, leading to an inscriptive disengagement that may not be pleasurable to those finding escape at the cinema.

With film entering the digital age, the opening sequence, with its position at the filmic edge, turns the window as frame to a door as threshold, which Elsaesser, following Genette's cue on the peritext, states in his introduction to film theory. First, the motif of the door is crucial to contemporary exegesis because it leads to the analytical dimension of cultural discourses, indicating how the encrypted information received has contradictory fissures that require analytical stitches, and, second, this hermeneutic plane leads, at the film's conclusion, to "nothing other than the original void", an originary absence that will be elaborated by way of Jean Pierre Oudart's Lacanian concept of "suture" because it primarily focuses on cinematic workings, theoretically explaining how the immersive process of film narrative works.

I shall rework Oudart's explanation in order to articulate something about "subjective" cinema, human individuals becoming subjects only by being subjected ideologically, which, in the psychoanalytic sense, means that it is an absence at the textual core that gives space to the substantiating presences of narrative voices composing the filmic texture, which George Butte's "Suture and the Narration of Subjectivity in Film" addresses by redirecting Oudart's filmic suture to Maurice Merleau-Ponty's figure of the chiasmus as an interweaving of narrative presences, a structure not unlike the hyperlinked configuration of the internet. Butte's paper is significant because of his allusion to what he calls an "evasion of the experience of lack" with a viewing process that, as the continuity editing of Hollywood indicates, is constructed in a way that encourages vicarious enjoyment. His theoretical engagement with Merleau-Ponty's phenomenological reading of the psychology of film centres on the "nested frames of consciousness responding to consciousness in narrative that [he calls] 'deep intersubjectivity" (Butte, 2008), which brings to mind the appearance of harmonious communication among different characters and viewers, implied or actual. However, he does not highlight the fact that Merleau-Ponty's phenomenological approach to film clearly underscores that this new psychology is one founded upon 
"cinematographic illusion", which recalls Myer's theoretical concern of the turn from imaginary performance to social performance, a filmic to post-filmic move. The presences to which the former refers are not presences as traditionally understood; they are constructed presences just as identity, gender or otherwise, can be considered a social construction.

\section{The Cyborg Insurgency: A Workers' Revolution?}

The epigraph from Karl Marx's Grundrisse informs this section because I shall address the socialist side of Haraway's "A Cyborg Manifesto" before I go on to discuss how its revolutionary potential goes beyond contemporary feminism. Cyberfeminism, although still an approbate for the repressed third-world females, albeit those privileged enough to know that there are alternative realities to the oppressive one within which they find themselves, may not be that valid for the twenty-first century urbanised centres. If one has to deal with the question of the feminine, I would rather follow the Derridean lead by not repeating the phallocentric move in turning gynocentric because the zero of the female requires the one of the male in order to acquire the propriety of sense, aptly aligned to the contemporary uses of computerised code encryption called "bits". Thus not only do we have to think of how to approach the question of the feminine that surpasses the issues of anatomy and biology, we would also have to find legitimate ways to counter acts of domination. Perhaps one should think in terms of a type of empowerment that grants not just agency to any oppressed individual, male or female; it is an avowal of the human individual's natural rights as universally declared.

This is in line with Sylvie Fogiel-Bijaoui's insistent political calling for "the principles of equality and human dignity" $(2016,7)$ that female "substantive representation" accords. In other words, a woman's formal rights to participation and political representation encompass her rights to be a part of the society within which she lives as well as the right to be different (2016, 5). Fogiel-Bijaoul's borrowed Ulrich Beck's concept of cosmopolitanisation which she explains: "cosmopolitanisation as lived experience often implies some individual or collective change, which is itself often unintended. Encounters with alterity may not be a sheer pleasure but people must develop a habitual readiness to cope with them. So, clearly experience of diversity fosters the ability to alter life scripts prewritten by any community - of faith, tradition, religion or culture - and to draw selectively on a variety of different cultural repertoires" (2016, 2, emphasis mine). In other words, we have to be discerning not only in our lifestyle choices; we should exercise our judgements in what we (re)produce, thereby invoking the right to be recognised for our labour and not be coerced into becoming anonymous reproductive surrogates for others.

The aforementioned pertains to hyper-industrialisation wherein the technological process of controls the entire production. What occurs is the appropriation of living labour, a phenomenon that leads to the objectification of living labour: "the transformation of the means of labour into machinery" and of "living labour into a mere living accessory of this machinery" (Marx, 1973, author's emphasis). Living labour normally provides supervision to the production process. However, according to Marx, industrialisation means that the machine moves the unity of the production process, overtaking the static unity of the product itself and becoming "living machinery" (Marx, 1973). It controls the structures of production that, in turn, influences the economic organisation of society, leading to the instrumentalisation and dehumanisation of living labour. What Marx does not anticipate is the radical industrialisation that has occurred from the beginning of the $20^{\text {th }}$ century onwards 
whereby such objectification of "living labour" does not only affect the industrial and manufacturing sectors; it has apparently permeated all the organisational structures of capital. The Marxist critique of industrial alienation stems from the fact that the proletariat does not have a share in the production profits, a tenuous existential state worsened by the lack of recognition for their contributions. They are perceived as mere cogs in an industrial wheel, each playing a role in the mass production of commercial goods.

With a global move from industrialisation to information technology, which occurred sometime around the middle of the twentieth century, alienated work can extend to those employed in the information sector. The films discussed here are cinematic commentaries on the incessant demands of service, resources and labour by global modernity. This also includes technologised militarism, (wo)man turned into weaponry for the destruction of the state's enemies, an idea visually represented by the construction of a female cyborg warrior in the opening sequence of Ghost in the Shell. While Marx wrote in the late nineteenth century to contest the inherent economic exploitation of labourers by the capitalists, the Frankfurt School, in the middle of the twentieth century, discursively intervened the capitalistic control of culture. Qualifying that Theodore Adorno's and Max Hockheimer's critique is not against popular culture per se, I shall gesture to their political rhetoric as challenges not only against the ideological hold of the extensive production of popular culture or the use of mass communicative technologies for propaganda but also the proliferating uses of art or science for commercial or economic purposes.

The Frankfurt scholars exposed the inherent irrationality behind the Nazi instrumentalisation of reason, an irrationality that now concerns post-industrialised societies in the form of information flows via communicative networks: in other words, the technological uses of mass communicative objects such as the radio and the television for ideological control, an issue made evident by the widely disseminated telecasts of propaganda speeches in the past and the seductive television commercials in the present. In an era of the "politics of lifestyle", wherein the lifestyle one chooses is reflected in how one accessorises, the relevance of "Culture Industry: Mass Deception as Enlightenment" can be found in its critique of the commercialisation and standardisation of capitalistic activities, the apogee of which is the advertising of commercial products found on billboards, magazine advertisements and television commercials et cetera, and how these marketing strategies hone in on the ideological instilling of false needs in order to promote commercial consumption. Notwithstanding my sometimes consensual commercial participation, myself admittedly affirmative of the move to digitisation, it is important to educate the young in exercising judgement whenever they access the internet, go into the city, drive along the highways or turn on our audio-visual equipment at home. In other words, we cannot simply ignore the ubiquity of commercial advertisements, although one can actively resist these public temptations at every turn, uncluttering our minds.

What then comes to the fore is the Enlightenment advocacy of treating living individuals as ends in themselves and not means, a maxim substantiated by the latent text of Burton's Big Eyes wherein Margaret Keane is coerced into working sixteen hours a day in order to upkeep her spouse's lifestyle. Having noted Burton's unbiased attitude towards Margaret Keane's paintings, an indisputable democratic premise that underpins popular culture, Burton's amusing but acerbic portrayal of Walter Keane, a genius in marketing, satirises the unthinking reception of popular culture. And yet implicit in Burton's film is the recognition of the ineluctable economic aspect of any artistic endeavour; it appears that capital will always win when the question of survival is broached. 
When asked about the subjects of these paintings, Keane responds that he is inspired by the orphaned in post-war Europe. His answer is clearly an unmistakeable selling tactic, attestating to capital's triumph. Where Margaret Keane is concerned, there is only the enigmatic "the eyes are windows to the soul". Perhaps a psychoanalytic reading will shed some light on her vulnerability in the chauvinistic cultural environment of the mid-twentieth century, visual portrayals symbolic of the artistic and domestic repressions she has felt living at the end of an era that was defined predominantly by the professional invisibility of women. Set in the nineteen-sixties artistic niche of San Francisco, the film also wryly explores the rise of the postmodernist American culture, giving us alternating aesthetic appreciations from the elitist art critics such as The New York Times John Canaday, who sneered at Keane's "infinity of kitsch", and the opportunistic local newspaper writer, Dick Nolan, who uses the mass allure of Margaret's painting as a newsworthy angle. Burton's neutral attitude towards artistic "kitsch" is evident with the fact that he starts the opening scene with Andy Warhol's commemoratory statement on how Margaret Keane's paintings must be artistically successful because the masses adore them, signalling the postmodern emphasis on repetition, given the modern availability of mechanical reproduction enabled by copiers, cameras and computers.

Walter Benjamin's "The Work of Art in the Age of Mechanical Reproduction" espouses technological advancements because these provided changed conditions to reproduction, revolutionarily meeting the political demands of aesthetics even as his Marxian reference indicates an ambivalent attitude towards the progress made by mechanical reproduction. According to Benjamin, "Marx directed his efforts in such a way as to give them prognostic value. He went back to the basic conditions underlying capitalistic production and through his presentation showed what could be expected of capitalism in the future. The result was that one could expect it not only to exploit the proletariat with increasing intensity, but ultimately to create conditions which would make it possible to abolish capitalism itself" (Benjamin, 1969). These changed conditions also slowly transformed the socio-political superstructure the effects of which are "manifested in all areas of culture" (ibid). The cultural impact of mechanical reproducibility can be felt in his comment: "Even the most perfect reproduction of a work of art is lacking in one element: its presence in space and time, its unique existence at the place where it happens to be" (ibid), covertly reinforcing the notion of artistic authenticity. His subtle critique of the technological reproducibility of works of art can be detected when he informs us that "[t]he presence of the original is the prerequisite to the concept of authenticity" (ibid), inadvertently putting to question the mechanistic dissemination of prized artworks, previously valued for their authentic artistic techniques and material embodiment of creative ideas, with the discursive use of the word "depreciated". To Benjamin, the Marxian critique of the political economy of capitalism inherently predicts a proletarianised future of even works of art. Whereas the rest of Benjamin's text on mechanical reproducibility appears to argue for its democratising potential, the possibility of which is found in its ability to visually simulate and make accessible that which was previously available only to the upper classes: "One might generalise by saying: the technique of reproduction detaches the reproduced object from the domain of tradition" (ibid), I sense a critical undercurrent that gestures to the problematic within the representational aspect of visual arts, one exacerbated by mechanical reproducibility, which is of import to artistic appreciation. First, the discourse indicates the possibility of misappropriating these artworks for commercial purposes and, second, it is this simulative dimension that provides the conditions for financial manoeuvrings. 
Citing extensively Benjamin's introductory sections on authenticity has something to do with this intuition of another level of connotation when it comes to technological reproducibility. By emulating our natural instinct to reproduce, the conditions given by this possibility of multiple copies could also be the cause for identity displacement, an ontological issue made obvious in the artistic supplanting of Margaret Keane by a marketingsavvy Walter Keane and the extra-diegetic character shift from Major Motoko Kusanagi of the 1995 filmic original to Major Mira Killian who finds out that her real identity is Motoko Kusanagi in the 2017 live-action remake. Such displacing acts, which paradoxically destabilises filmic identity, is a process that also changes the term "frame-by-frame" to the "frame-to-frame" denotative narratological process in order to bring about the appearance of seamless story-telling. On a connotative level, this "frame-to-frame" process enables a shift from mere story-telling to the theoretical act of narratological analyses that take the filmic to the post-filmic plane of reviews, commentaries and journal article.

Burton's Big Eyes opens with a visual metaphor of the capitalistic manipulation of artworks, whereby a painting of a child with exaggerated, teary eyes is subjected to mechanical reproduction. This mise en scene of Margaret's painting being reproduced into cheap posters on a massive scale is an ironic illustration not that dissimilar to Benjamin's discussion on the mechanical reproducibility of artworks, a visual vignette of incessant technical replication occurring for capitalistic gains. It corresponds to Benjamin's description of how the masses desire to "get closer" to works of art they find appealing, an idea that Walter Keane himself uses to justify his actions, "People don't care if it is a copy. They just want art that touches them". How can art as rote repetition touch us emotively when we can see exact copies hanging on the walls of every contemporary bourgeois? Technological reproducibility provides the conditions for the economic abuse of Margaret Keane's paintings; it is means to extract some kind of sameness even from that which is artistically unique, an analogous treatment that corresponds to the exploitation of Margaret Keane herself, who becomes a metaphor for the living machine, an accessory that churns out paintings after paintings.

With the ability of endless multiplying, technological reproducibility "substitutes a mass existence for a unique existence. And in permitting the reproduction to reach the recipient in his or her own situation, it actualises that which is reproduced" (ibid). To give Benjamin credit, he attempts a reinterpretation of mechanical reproducibility by pointing to how modes of perception are activated when viewers look at the artistic copies, allowing and actualising new perceptual structuration. Whether this new organisation of perception materialises a remarkable piece of art is another matter. If there is any theoretical affirmation of mechanical reproducibility at all, it is Benjamin applauding the accessibility of visual pleasure given by technological advancement even as his writing evinces an ambivalent attitude toward the possibility of reproducing countless copies, implicitly acknowledging the fact that the mechanical reproduction of artworks erodes its aura and thereby its authentic value.

Margaret's initial acquiescence to her husband's commercial machinations can be attributed to the financial concerns she has. She is later bullied into locking herself in a room so that she produces hundreds of paintings for which Walter Keane takes credit. This relationship subsequently turns sour because of the falsehoods that underscore their business partnership. The hallucinatory episode she experiences at the supermarket indicates her repressed psychic condition after years of living a lie, not having any authentic, meaningful social contact. The edutainment value of the aforementioned filmic works of art can be found 
in their provocation of a social awareness of how domination, male or otherwise, found in the demands for mindless reproduction can lead to estranged labour, thereby having negative effects on the psychic state of urbanites living in the twenty-first-century cities.

The second half of the twentieth century saw the emergence of socialist feminism in a brand of cyberfeminism introduced by Haraway and other feminist standpoint theorists such as Hilary Rose and Sandra Harding, leading to the post-cyberfeminism of the twenty-first century. Post-cyberfeminism does not depart from Haraway's original premise. Instead it radicalises her theoretical emphasis on cyberspace as a site of essential emancipation. Their theories are premised on the relations between the production of knowledge and the practices of power. These feminist theorists challenged patriarchal power relations by focusing on socially situated knowledge out of which a standpoint can be made, advocating a political activism that liberates women from the concomitant patriarchal underpinnings of Western Enlightenment. Due to the theoretical attention given to Oshii's and Sander's opening versions of Ghost in the Shell, Haraway's socialist cyberfeminist discourse in "A Cyborg Manifesto" struck a resonance in an era when the place of many women was still in the domestic arena. Having said that, a recent reading of this text has found some of Haraway's writing dynamic and inspiring, a metaphorical writing that attempts to go beyond gender, race or class restrictions and, more importantly, alienated labour: "The cyborg is a condensed image of both imagination and material reality, the two joined centres structuring any possibility of historical transformation... The cyborg is a creature of the post-gendered world; it has no truck with bisexuality, pre-oedipal symbiosis, unalienated labour or other seductions to organic wholeness through a final appropriation of all the powers of the parts into a higher unity" (Haraway, 1991, emphasis mine). My emphasis in this citation from Haraway's "A Cyborg Manifesto" explains not only the significance of the Lacanian "suture", a reparative stitch of the Imaginary and the Symbolic but also the ultimate upending of Haraway's affirmative discourse, already intuited in Oshii's dystopian world. This psychoanalytic notion will demonstrate how a subject's imagination and the surrounding material reality, in Haraway's vocabulary, can be connected in and through a filmic imaginary, explicated with the filmic concept of diegesis. Thus the frame is in place for a de-framing performativity; this "raking of the frame" gives to a reading in the form of $a$ cinematic enonce, according to Oudart, whether in the form of a filmic narrative or a cultural aesthetics. Suture, a theoretical conception first introduced by Jacques-Alain Miller was appropriated later by Oudart for describing the process of film viewing, which when reinforced by the diegetic filmic notion, points to a bridging by the objet petit $a$, a communicative connection in lieu of a gap found right at the edge of the mise en scene, what the poststructuralists call the radical boundary, radical because it simultaneously permits the divergence and convergence of the inside and the outside.

This psychoanalytic absence at the limit is not the categorical separation that we understand normatively; it is a consequence of the symbolic residing within the imaginary and the imaginary within the real, evincing an empty locus because of multiple erasures, the primordial lack, denoted by Scott's 1982 opener, functioning as provocation to filmic reading, which at the perceptual level, can be theoretically called the film narrative. This level of narrativising can be brought to a different level motivated by the film critic's desire for analysis. This paradoxical motif of absence at the edges can be explained by the filmic gaps which the opening sequence allegorises in the manner which it is designed, a manner that gestures to the Freudian dream-work with its concepts of condensation, displacement, and secondary revision, a dream sequence that is made evident by the surrealist superimposition of images, directly reminiscent of Rene Magritte's and Salvador Dali's paintings, in the opening sequence to the latest Dick's short-fictional inspired anthology, 
Electric Dreams, an opening quite distinct from Scott's not only in terms of atmosphere; its staccato visual insertions and imagistic uses of the "eye" note the visual aspect of the viewer's gaze and its subsequent narrative appropriation. Moreover, the multiple appearance of this "eye" motif implies a returning gaze coming from within the screen, an anonymous other gazing at the viewer's gaze, heightened by a chromatic, laser-lit shot that viscerally draws the gazing into the screen.

Because of its artistically seductive array of imagery, our perceptual consciousness is pushed to the next level in an interpretative attempt, a metafictional level that analyses the visual language with focus given to the different intensities and textures of filmic signification. Thus Myer's "contextual imaginary" is located along the axial line connecting the Symbolic and the Imaginary in Lacan's psychoanalytic triangulation. This discussion notes that the Symbolic is alternatively called the Law-of-the-Father and the Imaginary is aligned with the maternal, which in Oshii's Ghost in the Shell, is symbolised by the psychic union between the feminised Major and the masculinised Puppet-Master - despite the much commented transgender traits of the latter - embodied in a young female at the conclusion of the film.

Haraway's cyberfeminism holds in tension the two perceptions underpinning the possibility for identity formation in cyberspace: she recognises that this male-dominated site also provides female users immense potential in undermining gender inequality and space for identity recreation. Following O Correa's citation of Catherine Belsey in her review, it is not anatomical or biological equality that women seek but the commensurateness in power. This remark is critical to an analysis of the visually dynamic illustration of the physical prowess of Kusanagi in the opening scene of Oshii's 1995 adaptation of Shirow's manga of the same title, realistically fleshed out by the biomechanical construction of Major in Sander's 2017 Ghost in the Shell, a female protagonist with a human brain encapsulated in a synthetic shell. A critical inquiry into the physiological appearance of the female protagonist and the number of images of Kusanagi's nakedness are shown in the animated film proper disavows any feminist potential of A Ghost in the Shell. These depictions of female nudity appear not only to reinforce the biological inequality between man and woman; they actually confirm that rousing desire is key to commerce. Sander's version, on the other hand, ensures that Major's mechanised body appears enclosed in an artificial shell. It is disappointing that the latter omits the scene wherein the animated (wo)man-machine figure twirls in a foetal position before emerging from her aqueous womb. In fact, Sander's version visually and atmospherically evoke the opener to Jonathon Nolan's and Lisa Joy's 2016 Westworld, an adult theme park which is, in essence, a world rather than a theme park, to paraphrase one of its creators. This not only indicates the importance of worldliness given by the painterly of digitisation but also how the robots are similarly flayed anatomically even as their synthetic construction gradually unfolds in the title sequence, which is remarked in the seventh episode title of its second season, "Les Ecorches", meaning "flayed".

Created by a representative from Hanka Robotics, a government-funded corporation involved in the experimental hybridisation of the synthetic and the organic to produce technologically augmented soldiers, Major joins an anti-terrorist unit, known as section 9, to fight cybercrimes. In order to do this, the cyborg-crime fighters have cable ports installed at the back of their necks so that they can "plug in" for a cybernetic deep dive into the synthetic minds of their enemies for information retrieval. It is the diving into a geisha's robotic brain that her psyche is hacked by her nemesis, the Puppet-Master, thereby allowing the latter to gain the upper hand, prompting her to rediscover her past. Sander's version makes 
pronounced Major's ontological estrangement, brainwashed and unknowingly suffering from a stolen identity, her organic brain has been fed memorious details that are not her own. Without a past that she possesses, memories that make her who she is, Major becomes psychically disturbed, at various filmic moments, by her resemblance to the synthetics she fights. Becoming an instrument of combat, she is easily manipulated by Dr Ouelet, the robotics specialist answering to Hanka Robotics, who advises her that memories do not define her, it is her actions that do.

Human consciousness is informed by memories which, in turn, affect perception and behaviour. This means that our perception will also influence our actions. Our sense of self is determined by both thoughts and actions, not just one or the other. According to the standpoint feminists, we should take a political stance even if one can be informed only in a socially situated manner, standing for and by what we believe in. Butte, in his historical contextualising of the Lacanian suture, refers to Kaja Silverman's and Danial Dajan's apparently irrelevant discursive takes on the concept, which delve into the Althusserian dimension of the filmic suture. I shall suggest that if we are speaking of how film narratives incite action, then this belief in a cause, political or otherwise, is that which makes us ideologically subjected and thereby a subject in our subsequent performativity. This means that the notion of ideology cannot be ignored when discussing agency and action, the very vocabulary of "subjectivity".

Standpoint feminism propounds a polemic stance due to its attention to power relations. This theoretical assertion is laudatory, given that, in general, political activism means acting or speaking against the dominant ideology without complete knowledge, forgetting that there is always a taint in the mirror of politics. Major's negative response to Dr Ouelet's encouragement that she is the first of her kind and the future of humankind implies a disconcerted psychic state. Neither completely synthetic nor fully organic, Major feels isolated despite the many reminders that she has a "ghost". In the cyber-universe of Ghost in the Shell, an individual with a "ghost" means that she, unlike the other robotic entities, has consciousness and concomitantly a soul. This testifies to the significance of having a mind, an inner space and a viscerous voice of one's own, to reiterate with a difference Virginia Woolf's "a room of one's own". With hindsight, the surreal images of opening sequences reiterate visually Joyce's and Woolf's poetic technique of stream of consciousness.

Sander's remake of Ghost in the Shell has been criticised for not rendering the philosophical leanings of Oshii's version well. But the opening sequence is an aesthetically astute rendition that demonstrates how Major's human brain can be connected artificially to the rest of her synthetic shell. It is via an advanced functioning neural network that sends physiological stimuli to the brain, which then disseminate brainwaves to the rest of the physical body. Physiologically, this does undermine the Cartesian duality because it demonstrates how our bodily pulsations affect the brain and vice versa. But how far can this physiological premise go when the title itself and the multiple references to Major's "ghost" indicate that human consciousness is the defining attribute of individual identity. Thus the Cartesian "I think, therefore I am" becomes validated rather than negated, further confirmed by Major's ironic reply to Ouelet's remark which implies that the replicative production on a massive scale her successful prototype makes her feel abandoned rather than treasured. 


\section{The Psychoanalytic Suture in Popular Culture}

Myer's theoretical thesis has as its fundamental the division between the filmic world and the real world. Conventionally, the opening sequence is designed to provide filmic hints to the viewers and it is through this filmic imaginary, expanded to a hierarchy of narrative levels, that plot and thematic connections can be made between the filmic world and the actual one. This transposing process means that cinematic intelligibility becomes enhanced by the film's illusory presence, a movement of the image to word as we tease out an interpretation from the writerly text so that we can get a readerly one. This description will be reiterated later albeit in a psychoanalytic manner. Myer's historical tracing from Plato's concept that unifies mimesis and diegesis to Genette's various definitions of diegesis, including the intra- and extra-diegeses, provides a comprehensive account of this literary and filmic term. It is, however, Paul Ricoeur's advice against the superimposition of mimesis and diegesis that is of interest here. This analytical concept not only explains the reason for the use of this phrase "the suspension of disbelief" in our viewing of film fictions, attesting to the imaginary as Plato's cave; it has ontological implications when referring to the filmic or realistic worlds. Intermingling the filmic mimetic and its counterpart, the diegetic, does explain the immersive experience of character identification and narrative projection. However, if we take as true the conventional view of films serving as "mirrors" to reality, then what follows will be Myer's "ideological black hole" that sucks in what is normatively known as reality as well, which the opener to the 1982 Blade Runner indicates.

In fact, one can say that this science-fictional opener may be prescient by virtue of the fact that the visual immediacy accorded by this unprecedented flow of information via communicative technologies has made RL almost indistinguishable from VR, an issue that Jean Baudrillard forewarns in his tirade against the hyper-simulation, making the endless, repetitive copying valueless, reinforcing Benjamin's concept of the aura and my argument that authentic self-consciousness is crucial to our existence in this contemporary, cosmopolitan world. One of the dangers of this visual proliferation making the spectacular the opiate of the masses is deception, making e-vices the prompters to cyber-security, which, judging from the notifications of improving changes in online security and privacy from Jstor and other commercial or non-commercial webpages, is the current topic of concern. While Myer does not include the revolutionary possibility given by digitisation, Haraway's theorising is the obverse. This ability to simulate reality to a level that makes the virtual more real than the real can be affirmative in provoking effective political activism, which Sander's version, criticised for its diluted, accessible adaptation of Oshii's filmic original, undeniably proposes. This digital transition, supported by Lev Manovich's theoretical elaboration in "What is Digital Cinema?", is reworked here by the discursive idea of "cinema", Myer's oxymoronic concept of "contextual imaginary", so as to indicate the gendered dimension of the Lacanian terms, something that Myer's chapter does not address. Manovich's thesis argues that the digital process of filmmaking takes cinema away from its photographic origin; the nature of its operation brings it closer to painterly techniques. The opening sequence of Oshii's Ghost in the Shell illustrates this painterly technique, with an imagistic making of the cybernetic body, what fans call "The Shelling Sequence", available online. Sander's version is comparably similar, another shelling that sequentially gives flesh to Oshii's version. Musically similar to the latter's iconic soundtrack of classical Japanese folk music imbued with a Hungarian flavour, Kenji Kawai, the original composer, is ushered in to recreate the score for the live-action remake, a haunting accompaniment to the divine iconicity in a cyborgian creation, sentient because of the organic brain installed in the humanlike carapace. The 2017 opening sequence differs from the 1995 sequence in these 
ways. The first has to do with the visual atmosphere. Oshii's version is more detailed, neoncoloured, and anatomically precise. Sander's version, darkened and therefore more cryptic in style, starts the visual depiction with the rising and merging of neural filaments, creating the cyborgian body's network significant to its physiological functioning. Both versions show a female figure rising to be enveloped in synthetic skin, which is followed by its metamorphosing to the almost complete human appearance. According to one of the fan websites, Oshii's version makes Major more doll-like than the female protagonist in the manga version. Sander's opening sequence takes a step further this doll-likeness, visually attesting to a sequence of scenes in Oshii's animated film where images of Motoko Kusanagi are juxtaposed with that of bare mannequins on a display window, ideologically implying that the synthetic shell which, by the way, belongs to Megatech, the animated film equivalent of Hanka Robotics in Sander's version, is that which leads to the objectification of an individual: Kusanagi as a female object of desire, Kusanagi as an instrumentalised cyborgian crimefighter, Kusanagi as the object of the psychoanalytic gaze. Thus the aforementioned film analysis demonstrates how cinematic movements can arise from the framed filmic shots, with the use of the word "cinematic" here indicating the discursive dimension of film studies.

Instead of photographic realism as its source, Manovich's article suggests to me that digital cinema, with a painterly origin, encourages the creation of diverse realities, making available realities other than the one we know and inhabit, a crucial statement attesting to the psychoanalytic concept of the imaginary, arguably a feminine notion. The filmic concept of diegesis, as explicated by Myer, examines how the exteriority of cinema affects the film's interiority or otherwise. This theorising of filmic covertness bears testament to this reading of the opening sequence as an aesthetic allegory of Myer's "contextual imaginary" that can contribute to a psychoanalytic rethinking of human consciousness, which the aforementioned films assiduously represent.

Despite Myer's detailed elaboration of how the filmic diegetic can be used to link imaginary action and social actions, it is not precise enough a critical address of what agency, autonomy and action mean, especially when the psychoanalytic concept of the imaginary is given its due attention. Strangely, Myer does not use the Lacanian-Miller psychoanalytic term, "suture", in his address of how film is crucial to this transference of imaginary action to social action. This term suggests that it is psychic triggers that motivate action - how signifiers attach themselves to our psyche - leading to consequences in our manner of being. This is something that commercial advertisers know and manipulate in designing their commercials. It is a tactic similar to the one used in propaganda wherein repetitive telecasts will ensure successful psychological instillation and manipulation. When alluding to cinematic projections, which the opening sequence is one instance, the process of suture, as expressed by Oudart, is activated by virtue of a doubling movement between two fields, the visual field of the imaginary, conventionally known as the diegetic space of the film, and an absent field which echoes the imaginary field, the extra-diegetic location of a symbolic field. This absent field, to the audience, is a subjective site that permits any viewer narrative structuration, an idea that Benjamin mentions in his essay on mechanical reproducibility but, in cinematic analysis, it is more a location of objectivity than subjectivity because this is where discursive linearity occurs. This momentary space is the place where the retroactively semantic is activated with the filmic signified presiding over a signifying exchange between the viewer and the viewed, a metonymic movement the crux of which is the exchange value of the iconic for the linguistic articulation of its message. Oudart states that "Thus what we are here calling the suture is primarily the representative of that which, under the same heading, is now used to designate 'the relationship of the subject to the chain of its 
discourse", a chainlike process that takes the imagistic over to the linguistic. It can function in an intra-diegetic manner as in the climactic scene of Big Eyes, wherein the courtroom drama not only presents to us a female victim filing a lawsuit against her husband for labour exploitation; it designates a shift from a visual text to a linguistic one and then back to the visual, a movement also reflected her performance, painting the waif paintings, during the first half of the film that moves to her verbal contestation at the law court followed by a returning visual performance in front of the judge and jury, a form of bearing witness to her abusive marriage.

The suturing operation, in psychoanalytic identification, stitches the viewer on the edge of the filmic exterior into the filmic interior so that the viewer, who is moved by the onscreen narrative of the female protagonist, becomes psychologically entangled with the filmic persona. For those who have suffered under patriarchal control, they will identify with Margaret Keane's initial anguish and applaud her later defiance of Walter Keane's hysterical domination. Comparably, most individuals who have experienced oppression will find psychic resonances in Major's characterisation and feel reinvigorated by her decision to fight bureaucratic control in a bid to regain her sense of self. The concept of suture, by way of its functioning, demonstrates the manner in which an engaged viewer can be turned into a subject. In terms of cinematic projection, it testifies to the allegorical nature of opening sequences so that the filmic experience can also be a profound, meaningful one. Whereas Myer's use of the word "imaginary" indicates the power of filmic narratives in provoking social action, the descriptive word "contextual" that comes before it implies thought, attesting to my earlier assertion that analysing and conceptualising human consciousness, which is of pertinence to personal or communal identity, can be a complex and intricate undertaking, an endeavour that proves that the cyberfeminists may be right in equating our brain functions to that of computation only because we are the ones who created computation in order to enable faster data analysis.

Digitalisation transforms our relationship with reality, a change symbolised by the "digital rain" found in Oshii's opening scene. This endless rows of encrypted codes that began as zeroes and ones, appropriated and made iconic by the Wachowski brothers in the Matrix trilogy, affirms the existence of different worlds, alternative realities no longer referential in the analogue sense. In coining the term, "differ-petit-ance", Myer's theoretical tribute to Derrida's "differance", another name for his "supplement" and Lacan's "objet petit a" does not attend to the feminine, explaining the significance of my attention to the imaginary here. If Oshii's shot of the digital rain signifies a cyborg's direct access to the cyber-net, then Derrida's "differance", a repetition-in-difference, is the word to note, a choral net-working, evanescently evoked by Kawai's music, that is more communal than individual, given his use of the word "chiasmus" in his "inter-view" with Christie McDonald, entitled "Choreographies". This concept is comparable to Butte's concept of "deep intersubjectivity". The imaginary does not subscribe to normative gender distinctions because it is psychically feminine in an artistic sense, in a way releasing anatomical difference, analogous to the transitional nature of the opening scene. These scenes not only reinforce the idea of the filmic frame; they, more importantly, testify to a void fundamental to artistic interpretations. In other words, these scenes can invoke filmic intelligibility, albeit derived from an aesthetic sensibility, which takes us from the imaginary to the symbolic by way of our propensity for narrative coherence and discursive cohesion. 


\section{Conclusion}

Instead of points of entry, the conclusion of this paper focuses on the opening scenes as points of exits, a critical move that attempts a beyond from that of imaginary identification or projections with attention given to the pleasures derived from cultural analyses. Most opening sequences are not designed in a linear fashion due to its brevity. The multiple functions of the title sequence stated earlier already imply that what the audience receive is thoughtful juxtaposition of images and words designed to create a signifying effect on the viewer. Thus opening sequences are cultural occurrences, imaginary sites re-turning as symbolic places, attesting to the Lacanian thesis that the psychoanalytic terms of the imaginary, symbolic and real are inextricably intertwined. These opening images can be received as mere flow of images to those who merely want entertainment, imagistic play to those attentive to them as visual creations or stylistic and thematic indicators to those whose intent is to analyse these images for commentaries. They provide, instead, hermeneutic satisfactions rather like the psychoanalytic processes of ego construction. The digital ability to transform frames to thresholds means that these enticing entries can also become signifying exits. This means that the screen as a framing device is tenable only as the Lacanian Mobius strip, a strip with a half-twist such that the inside becomes outside and the outside inside. The framing device is technically in place to enable both the narrative linking of filmic scenes at the denotative primary plane and the analytic exegesis from the connotative, secondary plane. In other words, the screen surface, although appearing contained, actually denotes a liminal situation, one indicating the proximity of narrative construction or the theoretical remoteness implied by film analysis, both a protective filter having intra-diegetic implications as well as the multiple discursive layering of extradiegetic commentaries, an artistic impasse that is the very condition for an aesthetic passage.

\section{References}

Adorno, Theodore and Max Hockheimer. "The Culture Industry: Enlightenment as Mass Deception." Retrived from http://faculty.georgetown.edu/irvinem/theory/AdornoHorkheimer-Culture-Industry.pdf

Baudrillard, Jean. (1994) Simulacra and Simulation. Michigan: The University of Michigan Press, pp. 1-42, 121-128.

Benjamin, Walter. (1969). The Work of Art in the Age of Mechanical Reproduction. Illuminations. Trans. Harry Zohn. Ed. And Intro. Hannah Arendt. New York: Schocken Books, pp. $217-252$.

Butte, George. "Suture and the Narration of Subjectivity." Retrieved from http://academic.csuohio.edu/kneuendorf/frames/editing/Butte08.pdf

Chun, Wendy Hui Kyung. (March-April 2000) "High Tech Orientalism." Matters of Representation: Feminism, Theory and the Arts Conference. Retrieved from http://www.brown.edu/Departments/MCM/people/chun/diss/c3.pdf

Derrida, Jacques and McDonald, Christie. (Summer, 1982) "Interview: Choreographies: Jacques Derrida and Christie V. McDonald." Diacritics. Vol. 12, no. 2, Cherchez la Femme Feminist Critique/Feminine Text, pp. 66-76.

Elsaesser, Thomas and Hagener, Malte. (2010) Film Theory: An Introduction through the Senses. London and New York: Routledge.

Fogiel-Bijaoui, Sylvie. (2016) "The Cosmopolitan Future: A Feminist Approach.” Law. Vol. 5, no. 3. Retrieved from https://doi.org/10.3390/laws5030034 
Genette, Gerard and Marie Maclean. (Spring, 1991) "An Introduction to the Paratext." New Literary History. Probings: Art Criticism, Genre, Vol.22, No. 2., pp. 261-272. CrossRef Haraway, Donna. (1991) "A Cyborg Manifesto: Science, Technology and Socialist Feminism in the Late Twentieth Century." Simians, Cyborgs and Women: The Reinvention of Nature. New York: Routledge, pp. 149 - 182. CrossRef

Harding, Sandra, ed., (2004) The Feminist Standpoint Theory Reader: Intellectual and Political Controversies. New York and London: Routledge, pp. 1-16, $67-102$.

Lacan, Jacques. (2007) "The Mirror Stage as Formative of the I Function as Revealed by Psychoanalysis." Ecrits: The First Complete Edition. New York: W.W. Norton and Company, 2007, pp. $75-81$.

Marx, Karl. Grundrisse. Marxists Internet Archive. Retrieved from https://www.marxists.org/archive/marx/works/download/pdf/grundrisse.pdf

Miller, Jacques Alain. "Suture: Elements of the Logic of the Signifier." The Symptom, Online Journal for Lacan.Com. Retrieved from http://www.lacan.com/symptom8_articles/miller8.html

Miner, Natasha. (2014) "Technology, Psychology, Identity: Ghost in the Shell and .hack//Sign." Electronic Journal of Contemporary Japanese Studies, Vol. 4, Issue 3.

Myers, Clive. (2011) "Theoretical Practice: Diegesis is not a Code of Cinema." Critical Cinema: Beyond the Theory of Practice. West Sussex and New York: Columbia University Press, pp. $11-40$.

O Correa, Marie Deanne Theresa. (August 2013) "Ghost in the Shell: A Cyborg-Feminist Review of Mamoru Oshii's Animated Film." Plaride, Vol.10, Issue 2.

Oudart, Jean Pierre. "Cinema and Suture." Lacan.com. Retrieved from http://www.lacan.com/symptom8 articles/oudart8.html

Roh, David S., Huang, Betsy and Niu, Greta A., ed., (2015) "Technologizing Orientalism: An Introduction." Techno-Orientalism: Imagining Asia in Speculative Fiction, History and Media. New Brunswick: Rutgers, The State University Press, pp. $1-22$.

Wagenaar, Wester. (2016) "Wacky Japan: A New Face of Orientalism." Asia in Focus. Retrieved from http://www.asiainfocus.dk/wp-content/uploads/2017/07/wackyjapan.pdf

Wilding Faith and Willis, Hyla. (2016) "SmartMom Rebooted: A Cyberfeminsist Art Collective Reflects on its Earliest Work of Internet Art." Retrieved from https://www.mamsie.bbk.ac.uk/articles/10.16995/sim.229/

\section{Films and Television Series}

Big Eyes. Dir. Burton Tim. The Weinstein Company, 2014.

Ghost in the Shell. Dir. Oshii Mamoru. Kodansha, Bandai Visual and Manga Entertainment, 1995.

Ghost in the Shell. Dir. Sanders Rupert. Paramount Pictures, 2017.

Westworld. Cr. Jonathon Nolan and Lisa Joy. HBO, 2016-.

Philip K. Dick's Electric Dreams. Cr. Ronald D. Moore and Michael Dinner. Channel 4 and Sony Pictures Television, 2017-. 